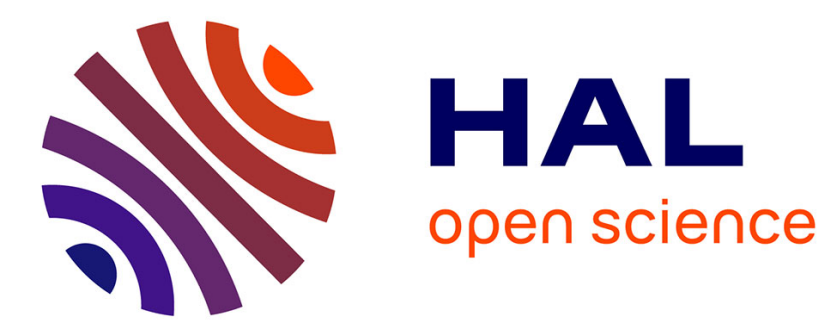

\title{
Distributed beamforming for wireless power transfer
}

Florin Hutu, Vincent Léchappé, Guillaume Villemaud, Michaël Di Loreto

\section{To cite this version:}

Florin Hutu, Vincent Léchappé, Guillaume Villemaud, Michaël Di Loreto. Distributed beamforming for wireless power transfer. URSI GASS 2020 - 33rd URSI General Assembly and Scientific Symposium, Aug 2020, Rome, Italy. pp.1-4, 10.23919/URSIGASS49373.2020.9232305 . hal-02916171

\section{HAL Id: hal-02916171 \\ https://hal.inria.fr/hal-02916171}

Submitted on 17 Aug 2020

HAL is a multi-disciplinary open access archive for the deposit and dissemination of scientific research documents, whether they are published or not. The documents may come from teaching and research institutions in France or abroad, or from public or private research centers.
L'archive ouverte pluridisciplinaire HAL, est destinée au dépôt et à la diffusion de documents scientifiques de niveau recherche, publiés ou non, émanant des établissements d'enseignement et de recherche français ou étrangers, des laboratoires publics ou privés. 


\title{
Distributed beamforming for wireless power transfer
}

\author{
Florin Huţu $^{(1)}$, Vincent Lechappé(2) Guillaume Villemaud $^{(1)}$, and Michaël Di Loreto ${ }^{(2)}$ \\ (1) Univ Lyon, INSA Lyon, Inria, CITI, F-69621, Villeurbanne, France \\ (2) Université de Lyon, Université Claude Bernard Lyon1, CNRS, Ampère, F-69622, Villeurbanne, France \\ e-mail: florin-doru.hutu@insa-lyon.fr
}

\begin{abstract}
With the technology progress, the amount of energy which is necessary to power supply the connected devices will decrease continuously. Providing the energy for such objects by the means of electromagnetic waves (wireless power transfer) becomes a feasible option. This paper tackles a particular method of wireless power transfer, which is the distributed beamforming. By simulation results, the paper highlights the impact on the received power level of the phase coherence and of frequency synthesis mismatch. Then, we present an experimental setup able to test wireless power transfer scenarios through distributed beamforming.
\end{abstract}

\section{Introduction}

All studies predicted an exponential increase of the number of connected devices (50 billion in 2020 [1]) in a multitude of applications related to agriculture, industry, health monitoring, etc. Even if this number was recently revised downward, it gives an idea of how important is to find new ways to reduce their energy consumption and so to decrease their environmental impact.

In many Internet of Things (IoT) applications, the use of classical energy source is inappropriate. One can cite the case of sensors buried in concrete that are monitoring the mechanical efforts inside the walls. The sensor life span will be strictly related to the battery lifetime. For these scenarios, the solution to transmit the entire or a part of the energy through electromagnetic waves may be taken into account. Indeed, this solution is feasible because of the increasing efficiency of the electronic devices. Some studies [2] are predicting that, in the next decade, the energy needed for a computational task will decrease by a factor 10000 compared to the current levels.

Wireless power transfer has already been proposed as a method to energize connected objects. Generally, the research is focusing at the receiver side, in order to increase the efficiency of the RF power rectifier since here is the main limitation. This efficiency is varying with respect to the received input power. With the current technology, in order to have a rectifier's efficiency greater than $25 \%$, the received signal should be superior to $-20 \mathrm{dBm}[3]$.
In order to increase the rectifier's efficiency, some recent works are focusing on the use of multi-carrier signals [4]. Indeed, such signals are renowned for having a high PAPR (Peak to Average Power Ratio) and to increase the DC voltage level at the rectifier's output [5]. Some other works are proposing a systematic view on maximizing the efficiency of the WPT by taking into account the power source, the effects of the propagation channel and the characteristics of the rectifier [6].

Wireless power transfer by using time reversal technology was proposed in [7]. This technique is based on spatialtemporal focusing effect. After a channel probing, made by sending an impulse signal, the transceiver will return a time-reversed, conjugate and amplified replica of the received impulse. These replicas will combine at the exact spot of the initial pulse, bringing there a relatively high amount of electromagnetic field energy.

Distributed beamforming has already been proposed as a way to maximize the wireless power transfer and some theoretical solutions are proposed [8]. Here, the authors are formulating the problem of maximizing the power delivered by a distributed antenna array to a receiver by taking into account the channel effects. A fixed-point algorithm is giving the optimum power allocations in a finite set of frequencies.

In distributed beamforming, a network of individual wireless nodes having single antennas are cooperating in order to generate synchronized signals. The considered sources may be Access Points (AP) in Wireless Local Area Networks (WLAN) or cellular base stations. The initial phase of the emitted signals are chosen such way that, in a desired spot, the phase coherence occurs. Consequently, the amplitude of the electromagnetic field is locally maximized. This paper gives an analysis of the impact on the received power of the synchronization and phase synthesis accuracy.

In Section 2, the distributed beamforming for wireless power transfer issue is formalized. Then, some simulation results are tackling the impact of different beamforming synthesis errors on the received power level. Section 3 presents an experimental setup built in order to validate the distributed beamforming scenarios. Conclusion and future directions are given in Section 4. 


\section{Problem statement and simulation results}

Consider $N$ identical sources randomly distributed in a Cartesian plane. Each source is defined by its coordinates $\left(x_{i}, y_{i}\right)$ where $i \in[1, N]$. Consider also that each source is able to generate a signal at a frequency $f_{0}$ and with an identical power level $P$. At the center of the coordinate system, a receiver having low energy resources is placed. The objective is to bring at this point a maximum amount of energy by emitting power levels below the limits imposed by the regulations.

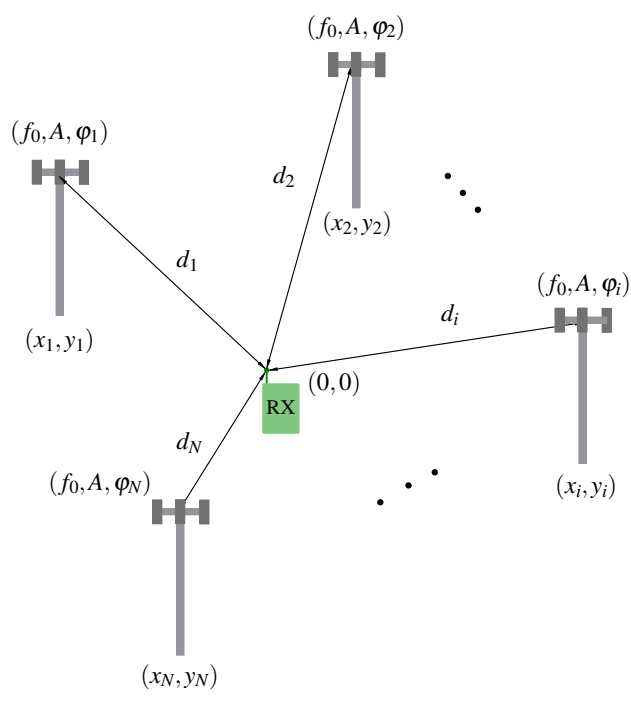

Figure 1. Scenario of wireless power transfer using geographically distributes RF sources

This receiver is power supplied by the electromagnetic field produced by the $N$ sources. As stated, the power of the received electromagnetic field is maximized if the arriving signals are in phase coherence. In order to obtain the phase coherence at the receiver level, the initial phase of the emitted signals should be :

$$
\varphi_{i}=\frac{2 \pi}{\lambda_{0}} \sqrt{x_{i}^{2}+y_{i}^{2}}
$$

where $\lambda_{0}$ is the wavelength of the emitted signals.

In the case of the phase coherence, the power level collected by the receiver increases with the number of sources. In the particular case where $N$ sources are placed at the same distance around the receiver, the gain, related to the power level received from one source can be expressed as :

$$
[G]_{d B}=20 \cdot \log _{10}(N) \text {. }
$$

In order to verify the theory, a simulator based on Keysight's ADS software was implemented. In this simulator, each source is placed at a certain distance from a sink and is able to deliver a CW (continuous wave) signal.
Between the different sources and the sink, free space, path loss propagation channel was considered.

If the scenario given in Table 1 is simulated, the received signals have an identical phase of 150.8 degrees and the received power level is $-33.04 \mathrm{dBm}$. In this particular case, the emitted power levels are of $-20 \mathrm{dBm}$ and antenna gains are $4.1 \mathrm{dBi}$. Cables connecting different antennas and having an insertion loss of $0.85 \mathrm{~dB}$ were also taken into account.

\begin{tabular}{|c|c|c|c|}
\hline Antenna & $\mathrm{x}$ (meters) & $\mathrm{y}$ (meters) & $\varphi$ (degrees) \\
\hline \hline 1 & -0.75 & 0.6 & 0 \\
\hline 2 & 0.75 & 0.7 & 68.2 \\
\hline 3 & -0.65 & -0.75 & 33.4 \\
\hline 4 & 0.85 & -0.85 & -108.2 \\
\hline
\end{tabular}

Table 1. Coordinates and the initial phases of the CW sources

Moreover, the simulator is able to test the impact on the received power of the frequency and phase synthesis deviation. Figure 2 presents the variation of the received power level if one of the emitter has a frequency deviation $\Delta_{f}$ with respect of the central frequency $f_{0}=868 \mathrm{MHz}$. One can remark that frequency deviations less than $\pm 25 \mathrm{kHz}$ must be guaranteed if power degradation of $1 \mathrm{~dB}$ with respect to the ideal case are desired.

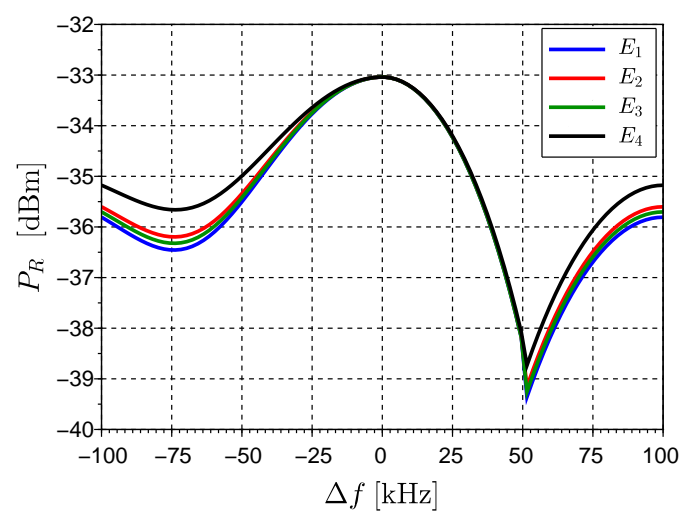

Figure 2. The power level variation with respect to the $\mathrm{CFO}$ (Central Frequency Offset)

Figure 3 presents the impact of the phase deviation on the received power. The received power level is insensitive on the phase synthesis since power diminutions of $1 \mathrm{~dB}$ are obtained for errors $\Delta \varphi$ greater than \pm 60 degrees, with respect to the ideal phase $\varphi_{i}$.

These simulation results are showing the importance of the synchronization between the different sources which seems to be more important than the phase synthesis. 


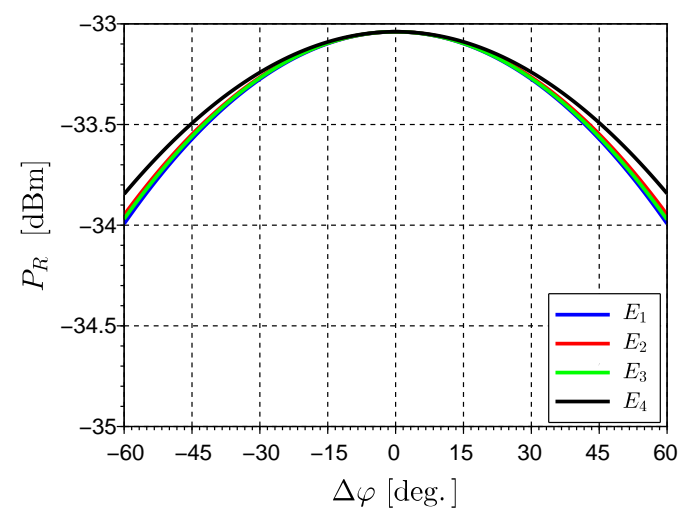

Figure 3. The power level variation with respect to the deviation of the desired phases $\varphi_{i}$

\section{Experimental setup}

A distributed beamforming scenario was implemented in FIT/CorteXlab testbed [9], a quasi-anechoic environment. A National Instruments' PXI chassis containing four 5645 VST's is the core of the experimental setup. The four VST (Vector Signal Transceiver) were used as CW generators and a spectrum analyzer was employed in order to measure the received power level.

Experiments were conducted at $868 \mathrm{MHz}$ and, as can be seen from Figure 4, four omnidirectional antennas have been connected to the VST's RF output. The antennas have a gain of $4 \mathrm{dBi}$, the coaxial cables have the same phase shift at $868 \mathrm{MHz}$ and the emitted power level was set to -20 $\mathrm{dBm}$, identical for the four VST. One receiving omnidirectional antenna has been placed at the center of a Cartesian coordinate system. The synchronization of the four VST and their phase coherence were tested beforehand.

The scenario presented in Table 1 was implemented and the received power level was approximately $-34.5 \mathrm{dBm}$, close to the simulated one. The difference between the simulated

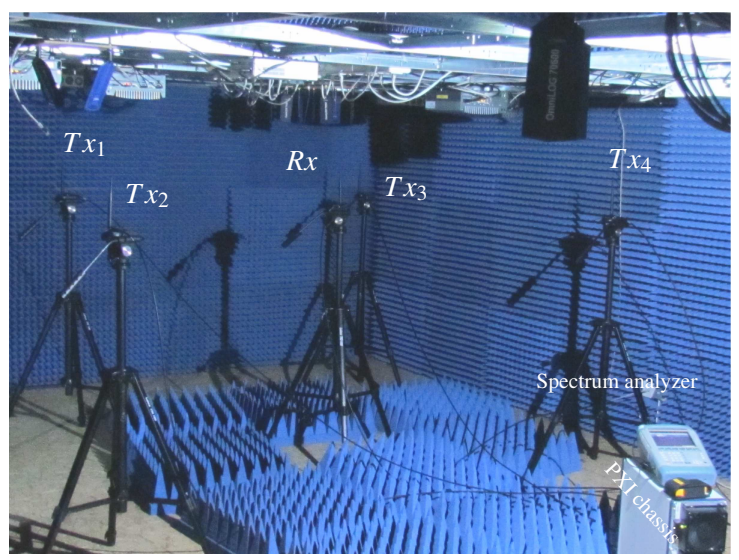

Figure 4. Measurement setup deployed in an quasianechoic chamber and measured received powers may come from the antennas gains disparity.

\section{Conclusion}

This article presented the distributed beamforming as a solution for wireless power transfer. After an analysis of the robustness in terms of phase and frequency synthesis error, the paper presented an experimental setup able to implement distributed beamforming scenarios. Future work will focus on implementation on the experimental setup of algorithms able to take into account the propagation channel impact.

\section{Acknowledgment}

This work was supported by the "Institut National des Sciences Appliquées" Lyon, France under the BQR 2019-2021 program.

\section{References}

[1] "More Data, Less Energy, Making Network Standby More Efficient in Billions of Connected Devices," International Energy Agency, 2014.

[2] J. Koomey, S. Berard, M. Sanchez, and H. Wong, "Implications of Historical Trends in the Electrical Efficiency of Computing," IEEE Annals of the History of Computing, vol. 33, no. 3, pp. 46-54, March 2011.

[3] Humberto P. Paz and Vinicius S. Silva and Eduardo V.V. Cambero and Humberto X. Araújo and Ivan R.S. Casella and Carlos E. Capovilla, "A survey on low power RF rectifiers efficiency for low cost energy harvesting applications," AEU - International Journal of Electronics and Communications, vol. 112, p. 152963 , 2019.

[4] R. Rousseau, F. Hutu, and G. Villemaud, "On the use of Vector Fitting and State-Space Modeling to Maximize the DC Power Collected by a Wireless Power Transfer System," in 2018 2nd URSI Atlantic Radio Science Meeting (AT-RASC), May 2018, pp. 1-4.

[5] A. Boaventura, D. Belo, R. Fernandes, A. Collado, A. Georgiadis, and N. B. Carvalho, "Boosting the Efficiency: Unconventional Waveform Design for Efficient Wireless Power Transfer,' IEEE Microwave Magazine, vol. 16, no. 3, pp. 87-96, April 2015.

[6] B. Clerckx, R. Zhang, R. Schober, D. W. K. Ng, D. I. Kim, and H. V. Poor, "Fundamentals of Wireless Information and Power Transfer: From RF Energy Harvester Models to Signal and System Designs," IEEE Journal on Selected Areas in Communications, vol. 37, no. 1, pp. 4-33, Jan 2019. 
[7] M. Ku, Y. Han, H. Lai, Y. Chen, and K. J. R. Liu, "Power Waveforming: Wireless Power Transfer Beyond Time Reversal," IEEE Transactions on Signal Processing, vol. 64, no. 22, pp. 5819-5834, Nov 2016.

[8] S. Goguri, D. Ogbe, R. Mudumbai, D. Love, S. Dasgupta, and P. Bidigare, "Maximizing wireless power transfer using distributed beamforming," in 2016 50th Asilomar Conference on Signals, Systems and Computers, Nov 2016, pp. 1775-1779.

[9] FIT/CorteXLab website. [Online]. Available: http://www.cortexlab.fr 